\title{
Erratum to: From Positive Orientation to Job Performance: The Role of Work Engagement and Self-efficacy Beliefs
}

\section{Guido Alessandri - Laura Borgogni - Wilmar B. Schaufeli • Gian Vittorio Caprara $\cdot$ Chiara Consiglio}

Published online: 3 July 2014

(C) Springer Science+Business Media Dordrecht 2014

\section{Erratum to: J Happiness Stud DOI 10.1007/s10902-014-9533-4}

The original version of this article unfortunately contained a mistake (the presentation of Figure 2 was incorrect; in fact a duplication of Figure 3). The corrected Fig. 2 is given below.

Fig. 2 Graphical representation of simple slope of the effect of P-OR on Job performance at different values of the moderator (work selfefficacy beliefs) with their corresponding confidence band. The horizontal line denotes a simple slope of zero. The vertical line represents the boundary of the region of significance

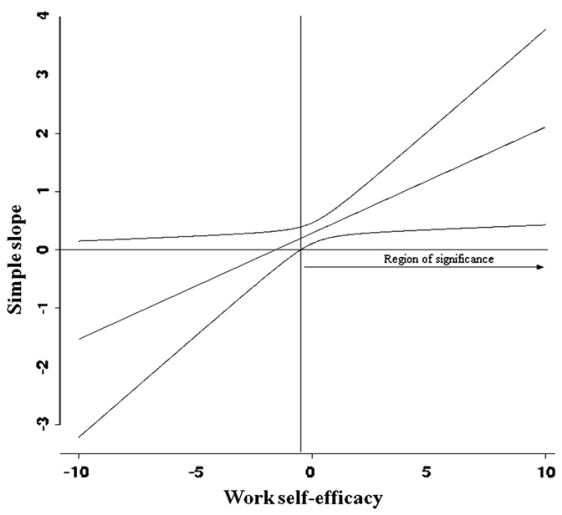

The online version of the original article can be found under doi:10.1007/s10902-014-9533-4.

G. Alessandri $(\bowtie) \cdot$ L. Borgogni · G. V. Caprara · C. Consiglio

Department of Psychology, Sapienza, University of Rome, Rome, Italy e-mail: guido.alessandri@uniroma1.it

W. B. Schaufeli

Utrecht University, Utrecht, The Netherlands 